Article

\title{
Interactions of Mycotoxin Alternariol with Cyclodextrins and Its Removal from Aqueous Solution by Beta-Cyclodextrin Bead Polymer
}

\author{
Eszter Fliszár-Nyúl ${ }^{1,2}$, Beáta Lemli ${ }^{2,3}$, Sándor Kunsági-Máté ${ }^{2,3}$, Lajos Szente ${ }^{4}$ and \\ Miklós Poór ${ }^{1,2, *}$ \\ 1 Department of Pharmacology, Faculty of Pharmacy, University of Pécs, H-7642 Pécs, Hungary \\ 2 János Szentágothai Research Centre, University of Pécs, H-7642 Pécs, Hungary \\ 3 Institute of Organic and Medicinal Chemistry, Medical School, University of Pécs, H-7624 Pécs, Hungary \\ 4 Cyclolab Cyclodextrin Research \& Development Laboratory, Ltd., H-1097 Budapest, Hungary \\ * Correspondence: poor.miklos@pte.hu
}

Received: 31 July 2019; Accepted: 27 August 2019; Published: 30 August 2019

\begin{abstract}
Alternariol is an Alternaria mycotoxin that appears in fruits, tomatoes, oilseeds, and corresponding products. Chronic exposure to it can induce carcinogenic and xenoestrogenic effects. Cyclodextrins (CDs) are ring-shaped molecules built up by glucose units, which form host-guest type complexes with some mycotoxins. Furthermore, insoluble CD polymers seem suitable for the extraction/removal of mycotoxins from aqueous solutions. In this study, the interactions of alternariol with $\beta$ - and $\gamma$-CDs were tested by employing fluorescence spectroscopic and modeling studies. Moreover, the removal of alternariol from aqueous solutions by insoluble $\beta$-CD bead polymer (BBP) was examined. Our major observations/conclusions are the following: (1) CDs strongly increased the fluorescence of alternariol, the strongest enhancement was induced by the native $\gamma-\mathrm{CD}$ at $\mathrm{pH}$ 7.4. (2) Alternariol formed the most stable complexes with the native $\gamma-\mathrm{CD}(\log K=3.2)$ and the quaternary ammonium derivatives $(\log K=3.4-3.6)$ at acidic/physiological $\mathrm{pH}$ and at $\mathrm{pH} 10.0$, respectively. (3) BBP effectively removed alternariol from aqueous solution. (4) The alternariol-binding ability of $\beta$-CD polymers was significantly higher than was expected based on their $\beta$-CD content. (5) CD technology seems a promising tool to improve the fluorescence detection of alternariol and/or to develop new mycotoxin binders to decrease alternariol exposure.
\end{abstract}

Keywords: alternariol; cyclodextrin; host-guest complexes; fluorescence spectroscopy; fluorescence enhancement; cyclodextrin polymers; mycotoxin binder; toxin removal

\section{Introduction}

Contamination of food and feed with mycotoxins has been an emerging problem worldwide. Alternariol $(\mathrm{AOH})$ is a dibenzo- $\alpha$-pyrone mycotoxin (Figure 1) produced by the phytopathogenic Alternaria fungi. Cereals, tomatoes, grapes as well as other soft-skinned fruits and vegetables are particularly susceptible for Alternaria infection [1]. Furthermore, $\mathrm{AOH}$ occurs as a contaminant in the corresponding processed products (e.g., wine and tomato juice) [2-4]. The concentration of $\mathrm{AOH}$ in different foods and beverages is in the 0.7 to $41.6 \mu \mathrm{g} / \mathrm{L}(2.7$ to $161.1 \mathrm{nM})$ range [5]. However, the extremely contaminated oilseeds can contain even $1000 \mu \mathrm{g} / \mathrm{kg}$ concentration of $\mathrm{AOH}$ [6]. The high thermal stability of Alternaria toxins makes their removal from foodstuffs difficult $[6,7]$. The $\mathrm{AOH}$ content of different foodstuffs and beverages is generally examined by HPLC (high performance liquid chromatography) linked to FLD (fluorescence detector), MS (mass spectrometer), or DAD (diode array detector), and stable isotope dilution assay (SIDA) methods [8-11]. Since AOH exerts fluorescence 
in aqueous solution, its molecular interactions can be effectively investigated using fluorescence spectroscopy [12].

Cyclodextrins (CDs) are ring-shaped oligosaccharides built up from six ( $\alpha$-CDs), seven ( $\beta$-CDs), or eight $(\gamma$-CDs) glucopyranose units, linked through $\alpha-(1,4)$ bonds [13]. The hydrophilic outer part of CDs provides excellent aqueous solubility, while their nonpolar internal cavity can accommodate lipophilic compounds [14]. The chemical modification of CDs affects their aqueous solubility and the stability of their host-guest type complexes, which properties are also influenced by the type and the degree of substitution $[15,16]$. CDs are extensively used by pharmaceutical $[15,17,18]$, cosmetic [19], and food industries $[20,21]$. Their applications include solubilization and stabilization (protection against light and oxidation) of compounds, improvement of the oral bioavailability of some drugs [18,22,23], and CDs can suppress unpleasant odors and/or tastes [20]. Furthermore, CDs are employed in environmental protection [24,25] and are also useful molecules in analytics [26,27].

Native and chemically modified CDs can form stable complexes with several mycotoxins, including aflatoxins, citrinin, ochratoxin $\mathrm{A}$, and zearalenone [28-31]. The complex formation can strongly increase the fluorescence of some mycotoxins, which makes possible their more sensitive fluorescence detection [29,31-33]. Furthermore, CD technology may be suitable for the development of new mycotoxin binders. Previous studies demonstrated that patulin, ochratoxin A, and zearalenone can be effectively removed/extracted from aqueous solutions (or even from beverages) with $\beta-C D$ polymers [34-37].

In this study, the interactions of $\mathrm{AOH}$ with native and chemically modified (methyl and quaternary ammonium derivatives) $\beta$ - and $\gamma$-CDs (Figure 1) were examined employing fluorescence spectroscopy and molecular modeling. $\mathrm{CD}$-induced enhancement in the fluorescence of $\mathrm{AOH}$ and the stability of $\mathrm{AOH}-\mathrm{CD}$ complexes were evaluated under different environmental conditions. Furthermore, the removal of $\mathrm{AOH}$ from aqueous solution by insoluble $\beta$-CD bead polymer (BBP) was also tested. Our results demonstrate that $\mathrm{CDs}$ strongly increase the fluorescence of $\mathrm{AOH}$ during the formation of stable host-guest type complexes; moreover, $\mathrm{BBP}$ can effectively remove $\mathrm{AOH}$ from aqueous solution.

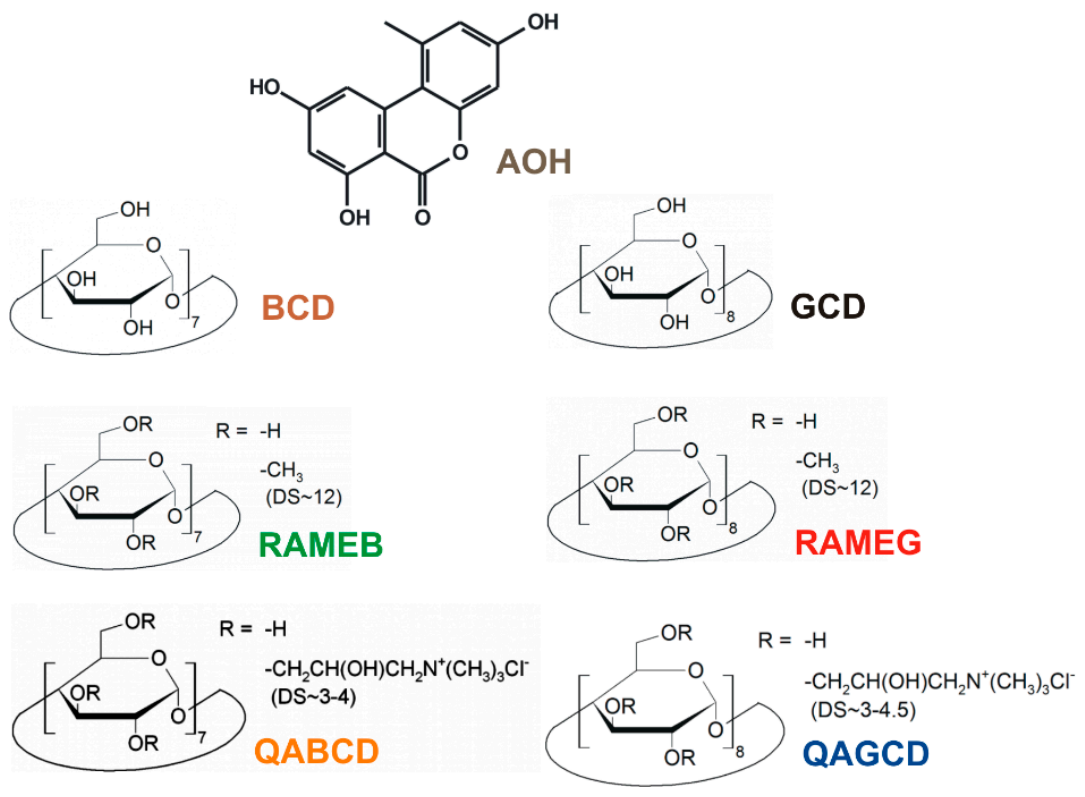

Figure 1. Chemical structures of alternariol $(\mathrm{AOH})$ as well as native and chemically modified $\beta$ and $\gamma$-cyclodextrins (BCD, $\beta$-cyclodextrin; RAMEB, randomly methylated $\beta$-cyclodextrin; QABCD, (2-hydroxy-3-N,N,N-trimethylamino)propyl- $\beta$-cyclodextrin; GCD, $\gamma$-cyclodextrin; RAMEG, randomly methylated $\gamma$-cyclodextrin; QAGCD, (2-hydroxy-3-N,N,N-trimethylamino)propyl- $\gamma$-cyclodextrin; DS: average degree of substitution per $\mathrm{CD}$ ring). 


\section{Materials and Methods}

\subsection{Reagents}

Alternariol (AOH) was purchased from Cfm Oskar Tropitzsch GmbH (Marktredwitz, Germany). Native and chemically modified CDs, including $\beta-C D(B C D), \gamma-C D(G C D)$, randomly methylated $\beta-C D$ (RAMEB), randomly methylated $\gamma$-CD (RAMEG), (2-hydroxy-3-N,N,N-trimethylamino)propyl- $\beta$-CD (or quaternary ammonium $\beta-C D, Q A B C D)$, (2-hydroxy-3-N,N,N-trimethylamino)propyl- $\gamma-C D$ (or quaternary ammonium $\gamma$-CD, QAGCD), soluble $\beta$-CD polymer (cross-linked with epichlorohydrin; BCD content: $70 \mathrm{~m} / \mathrm{m} \%$ ), and insoluble $\beta$-CD bead polymer (BBP; CD-epichlorohydrin cross-linked bead polymer; BCD content: $50 \mathrm{~m} / \mathrm{m} \%$ ) were obtained from CycloLab Cyclodextrin Research and Development Laboratory, Ltd. (Budapest, Hungary). HPLC-grade acetonitrile and methanol were purchased from VWR (Budapest, Hungary). Stock solution of $\mathrm{AOH}(5000 \mu \mathrm{M})$ was prepared in dimethyl sulfoxide (DMSO, spectroscopic grade; Fluka, NJ, USA) and was stored at $-20{ }^{\circ} \mathrm{C}$.

\subsection{Spectroscopic Studies}

Fluorescence spectroscopic measurements were carried out using a Hitachi F-4500 fluorescence spectrophotometer (Tokyo, Japan) in the presence of air, at $+25^{\circ} \mathrm{C}$. Samples with $\mathrm{AOH}(5 \mu \mathrm{M}=$ $1.29 \mathrm{mg} / \mathrm{L}$ ) and increasing amounts of CDs (final concentrations: 0.0, 0.25, 0.5, 1.0, 2.0, 3.0, 4.0, 5.0, 7.0, and $10.0 \mathrm{mM}$ ) were prepared in $50 \mathrm{mM}$ sodium acetate $(\mathrm{pH} 5.0)$, sodium phosphate $(\mathrm{pH} 7.4)$, and sodium borate buffers ( $\mathrm{pH} 10.0$ ). Since the aqueous solubility of BCD is lower vs. other CDs [38], the concentrations of BCD were the following: 0.0, 0.5, 0.75, 1.0, 1.25, 1.5, and 2.0 mM. Fluorescence emission spectra were recorded using $345 \mathrm{~nm}$ excitation wavelength, and the changes in the fluorescence emission of $\mathrm{AOH}$ was evaluated at $460 \mathrm{~nm}$.

Binding constants of $\mathrm{AOH}-\mathrm{CD}$ complexes were determined employing the graphical application of the following Benesi-Hildebrand equation [16,29,37]:

$$
\frac{I_{0}}{\left(I-I_{0}\right)}=\frac{1}{A}+\frac{1}{A \times K \times[C D]^{n}}
$$

where $K$ denotes the binding constant (unit: L/mol), $I_{0}$ and $I$ are the fluorescence intensity $\left(\lambda_{\mathrm{ex}}=\right.$ $345 \mathrm{~nm}, \lambda_{\mathrm{em}}=460 \mathrm{~nm}$ ) of AOH without and with CDs, [CD] is the concentration of the host molecule (unit: $\mathrm{mol} / \mathrm{L}$ ), $A$ is a constant, and $n$ is the number of binding sites.

To confirm the determined binding constants and binding stoichiometry of AOH-CD complexes, some experimental data were also evaluated applying the Scatchard equation (for the 1:1 complex formation) $[39,40]$ :

$$
\frac{\left(I-I_{0}\right)}{[C D]}=\left(I_{A O H-C D}-I_{0}\right) \times K-\left(I-I_{0}\right) \times K
$$

where $I_{A O H-C D}$ is the fluorescence intensity when total AOH has been complexed with CDs.

\subsection{Modeling Studies}

Molecular modeling studies have been performed at semi-empirical AM1 level using HyperChem 8 code [41,42]. After geometry optimization at AM1 level, the vibrational-rotational analyses were performed in harmonic approximation. Then, the enthalpy change of the complex formation was considered as the energy change calculated by subtracting the total energies of the reactants from the total energies of the products. Similarly, the entropy changes were calculated by subtracting the entropy terms of the reactants from the entropy terms of the products. To consider the overall effect of the entropy changes, the different terms of the entropy contents of all species were calculated applying the Boltzmann-statistics. For example, after calculating the vibrational frequencies using the harmonic approximation, the entropy was determined on the common way using the following HyperChem code [41,42]: 


$$
S_{v i b}=R \sum_{i}\left\{\frac{h v_{i} / k T}{e^{\left(\frac{h v_{i}}{k T}\right)}-1}-\ln \left[1-e^{\left(-\frac{h v_{i}}{k T}\right)}\right]\right\}
$$

where $v_{i}$ is the frequency of vibration and $T$ is the temperature $(298.16 \mathrm{~K})$. The stability constants were determined from the Gibbs free energy changes associated to the complex formation at $298 \mathrm{~K}$. A neutral aqueous environment was considered by the TIP3P solvation model implemented in HyperChem code (HyperChem, Hypercube Inc. 2007).

Cyclodextrin derivatives (QABCD, RAMEB, QAGCD, and RAMEG) were considered as charged species of the native molecules. Accordingly, the electron releasing property of the methyl groups were considered as negatively charged native $\mathrm{BCD}$ or GCD molecules, while the electron withdrawing character of quaternary ammonium moieties were considered as the positively charged native $\mathrm{BCD}$ or GCD.

\subsection{Extraction of AOH from Aqueous Solution with Insoluble $\beta$-Cyclodextrin Bead Polymer}

The removal of AOH by BBP was tested in four buffers ( $50 \mathrm{mM}$ sodium phosphate, $\mathrm{pH} 3.0 ; 50 \mathrm{mM}$ sodium acetate, $\mathrm{pH}$ 5.0; $50 \mathrm{mM}$ sodium phosphate, $\mathrm{pH} 7.4$; and $50 \mathrm{mM}$ sodium borate, $\mathrm{pH}$ 10.0). $\mathrm{AOH}$ $(2 \mu \mathrm{M}=516.5 \mu \mathrm{g} / \mathrm{L}, 1.5 \mathrm{~mL})$ was incubated in the presence of $0.0,1.0,2.5,5.0,10.0$, and $20.0 \mathrm{mg}$ BBP in a thermomixer (1000 rpm, $30 \mathrm{~min}, 25^{\circ} \mathrm{C}$ ). The insoluble beads were sedimented by pulse centrifugation ( $4000 \mathrm{~g}, 3 \mathrm{sec}$, at room temperature), and then a $500 \mu \mathrm{L}$ aliquot of the supernatant was diluted 1.5-fold with acetonitrile (before dilution, the samples at $\mathrm{pH} 10.0$ were acidified with $6.5 \mu \mathrm{L}$ of $3 \mathrm{mM}$ perchloric acid). AOH contents of these samples were quantified by HPLC (see in Section 2.5).

Using the same experimental conditions, increasing concentrations of $\mathrm{AOH}(0.2,0.5,1.0,2.5,5.0$, $7.5,10.0,12.5$, and $15.0 \mu \mathrm{M}$ in $1.5 \mathrm{~mL}$ buffer) were added to BBP (2.5 mg). Then, the AOH content of supernatants was determined. Using these data, the interaction of $\mathrm{AOH}$ with BBP was evaluated based on the Langmuir and Freundlich sorption isotherms [36,37]. The Langmuir equation is expressed as

$$
q_{e}=\frac{Q_{0} \times K_{L} \times C_{e}}{\left(1+K_{L} \times C_{e}\right)}
$$

where $q_{e}$ is the amount of bound $\mathrm{AOH}(\mathrm{mg})$ by BBP $(\mathrm{g})$, while $C_{e}$ is the amount of unbound $\mathrm{AOH}(\mathrm{mg})$ in the solution at equilibrium. $Q_{0}$ is the calculated maximum amount of $\mathrm{AOH}(\mathrm{mg})$ bound per $\mathrm{g}$ of $\mathrm{BBP}$, and $K_{L}$ denotes the Langmuir equilibrium constant $(\mathrm{L} / \mathrm{mg})$. The Freundlich equation is described as

$$
q_{e}=K_{F} \times C_{e}^{1 / n}
$$

where $K_{\mathrm{F}}$ is the Freundlich constant (unit: $\left.(\mathrm{mg} / \mathrm{g})(\mathrm{L} / \mathrm{mg})^{1 / \mathrm{n}}\right)$, while $n$ is the heterogeneity index.

\subsection{HPLC Analyses}

The $\mathrm{AOH}$ content of samples was determined applying a HPLC system (Jasco; Tokyo, Japan) built up by a binary pump (PU-4180), an autosampler (AS-4050), and a FP-920 fluorescence detector. Samples (with $20 \mu \mathrm{L}$ injected volume) were driven through a NovaPak C18 $(4.0 \times 3.0 \mathrm{~mm})$ guard cartridge linked to a NovaPak C18 $(150 \times 3.9 \mathrm{~mm}, 4.0 \mu \mathrm{m})$ analytical column. The mobile phase was $1 \mathrm{mM}$ orthophosphoric acid ( $\mathrm{pH} 3)$ and acetonitrile (60:40 v/v\%). The isocratic elution was performed with $1.0 \mathrm{~mL} / \mathrm{min}$ flow rate at room temperature, then $\mathrm{AOH}$ was detected at $455 \mathrm{~nm}\left(\lambda_{\mathrm{ex}}=345 \mathrm{~nm}\right)$. Chromatographic data were evaluated using ChromNAV software (Version 2).

2.6. Comparison of the Interaction of Alternariol with $\beta$-Cyclodextrin, Soluble $\beta$-Cyclodextrin Polymer, and Insoluble $\beta$-Cyclodextrin Bead Polymer at $\mathrm{pH} 3$

According to the manufacturer's description, the soluble BCD polymer and the BBP contain approximately 70 and $50 \mathrm{~m} / \mathrm{m} \% \mathrm{BCD}$, respectively. Therefore, we can calculate the molar concentrations 
of BCD which are contained by the applied amounts of soluble BCD polymer and BBP. In the following experiments, increasing amounts of BCD (final concentrations: 0, 0.25, 0.5, 1.0, 1.5, 2.0, and $2.5 \mathrm{mM}$ ) or soluble BCD polymer (final concentrations were equivalent to $0,0.14,0.35,0.7,1.4,2.1$, and $2.8 \mathrm{mM}$ of $\mathrm{BCD})$ were added to $\mathrm{AOH}(2 \mu \mathrm{M})$ in sodium phosphate buffer $(50 \mathrm{mM}, \mathrm{pH} 3.0)$. Then, the changes in the emission signal of $\mathrm{AOH}$ were recorded $\left(\lambda_{\mathrm{ex}}=345 \mathrm{~nm}, \lambda_{\mathrm{em}}=460 \mathrm{~nm}\right)$. According to these fluorescence data, the $\log K$ values were calculated employing the Benesi-Hildebrand equation (Equation (1)), assuming 1:1 stoichiometry of the complex formation.

Furthermore, based on the bound fraction of AOH in the presence of BBP (see details in 2.4 and 2.5), the $\log K$ values regarding $\mathrm{AOH}-\mathrm{BBP}$ interaction was also calculated assuming 1:1 stoichiometry.

$$
\begin{gathered}
A O H+C D \leftrightarrow A O H B C D \\
K=\frac{[A O H B C D]}{[A O H] \times[B C D]}
\end{gathered}
$$

where $A O H B C D$ denotes the 1:1 stoichiometry complex of $\mathrm{AOH}$ with $\mathrm{BCD}$, while $[A O H],[B C D]$, and $[A O H B C D]$ are the molar concentrations of unbound $\mathrm{AOH}$, unbound $\mathrm{BCD}$, and $\mathrm{AOH}-\mathrm{BCD}$ complex, respectively.

\subsection{Statistical Analyses}

Data demonstrate mean \pm standard error of the mean (SEM) derived from at least three independent experiments. Statistical significance was established based on the One-Way ANOVA test $(p<0.01)$ using the IBM SPSS Statistics software (Version 21; New York, NY, USA).

\section{Results}

\subsection{Effect of the Environmental $\mathrm{pH}$ on the Fluorescence Spectrum of Alternariol}

First, the fluorescence excitation spectra of $\mathrm{AOH}$ were recorded under acidic ( $\mathrm{pH}$ 5.0), physiological ( $\mathrm{pH}$ 7.4), and alkaline ( $\mathrm{pH}$ 10.0) conditions, using 417 and $465 \mathrm{~nm}$ emission wavelengths. Under acidic circumstances, the excitation maximum of $\mathrm{AOH}$ appeared approximately at $350 \mathrm{~nm}$. Then, with the elevation of the $\mathrm{pH}$, a slight blue shift $(350 \rightarrow 340 \mathrm{~nm})$ and the decreased intensity of this peak was observed (Figure 2A). Furthermore, at $\mathrm{pH} 7.4$, a second excitation peak appeared at $410 \mathrm{~nm}$, which became highly dominant at $\mathrm{pH} 10.0$ (Figure 2B).
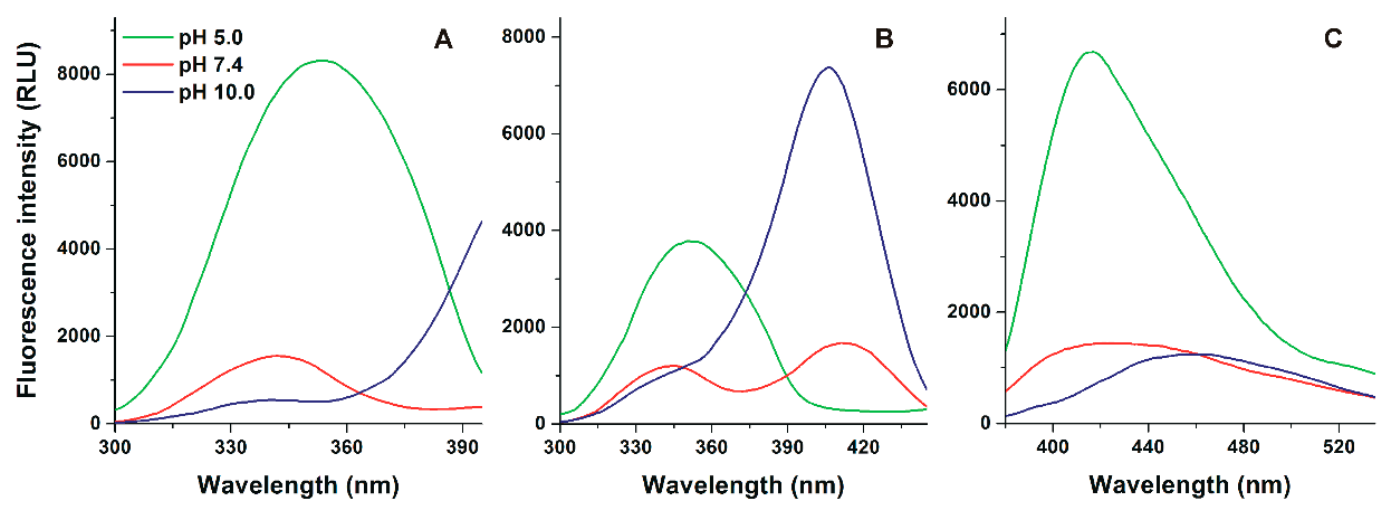

Figure 2. Fluorescence excitation (A: $\left.\lambda_{\mathrm{em}}=417 \mathrm{~nm} ; \mathbf{B}: \lambda_{\mathrm{em}}=465 \mathrm{~nm}\right)$ and emission (C: $\left.\lambda_{\mathrm{ex}}=345 \mathrm{~nm}\right)$ spectra of $\mathrm{AOH}(50 \mu \mathrm{M}=12.9 \mathrm{mg} / \mathrm{L})$ in sodium acetate $(50 \mathrm{mM}, \mathrm{pH} 5.0)$, sodium phosphate (50 mM, $\mathrm{pH}$ 7.4), and sodium borate (50 mM, pH 10.0) buffers (ex slit: $10 \mathrm{~nm}$, em slit: $10 \mathrm{~nm}$; RLU, relative light unit).

Emission spectra of $\mathrm{AOH}$ were recorded using $345 \mathrm{~nm}$ excitation wavelength. At $\mathrm{pH}$ 5.0, the emission maximum of $\mathrm{AOH}$ appeared at $417 \mathrm{~nm}$, while the red shift of the emission spectrum was 
observed with the elevation of $\mathrm{pH}$, showing emission maxima at 425 and $465 \mathrm{~nm}$ at $\mathrm{pH} 7.4$ and 10.0, respectively (Figure 2C). Using $410 \mathrm{~nm}$ excitation wavelength, a large emission peak was noticed approximately at $450 \mathrm{~nm}$, while this emission peak was significantly lower and missing at $\mathrm{pH} 7.4$ and 5.0, respectively (Figure S1).

\subsection{Effects of Cyclodextrins on the Fluorescence Spectrum of Alternariol}

To characterize the interactions of $\mathrm{AOH}$ with $\mathrm{CDs}$ (native, randomly methylated, and quaternary ammonium $\beta$ - and $\gamma$-CDs), fluorescence emission spectra of $\mathrm{AOH}$ were recorded in the presence of increasing CD concentrations using a $345 \mathrm{~nm}$ excitation wavelength. In the presence of CDs, a significant red shift in the emission spectrum of $\mathrm{AOH}$ was observed, and the AOH-CD complexes showed their emission maxima around 450-470 $\mathrm{nm}$ depending on the CD and the buffer used (Figure 3). Therefore, we selected $460 \mathrm{~nm}$ for the following comparison and evaluations (e.g., calculation of binding constants). At acidic and physiological $\mathrm{pH}$, noticeably two emission peaks can be distinguished in the presence of CDs (peak 1 around $410 \mathrm{~nm}$ and peak 2 around $450 \mathrm{~nm}$ ), as it is demonstrated in Figure 3 regarding GCD. This shape of the emission spectra was same in the presence of uncharged CDs (BCD, RAMEB, GCD, and RAMEG) at pH 5.0 and 7.4 (Figure 3A). However, at pH 10.0, peak 1 seems to be disappeared and a further red shift of the emission maximum was observed (Figure 3B).
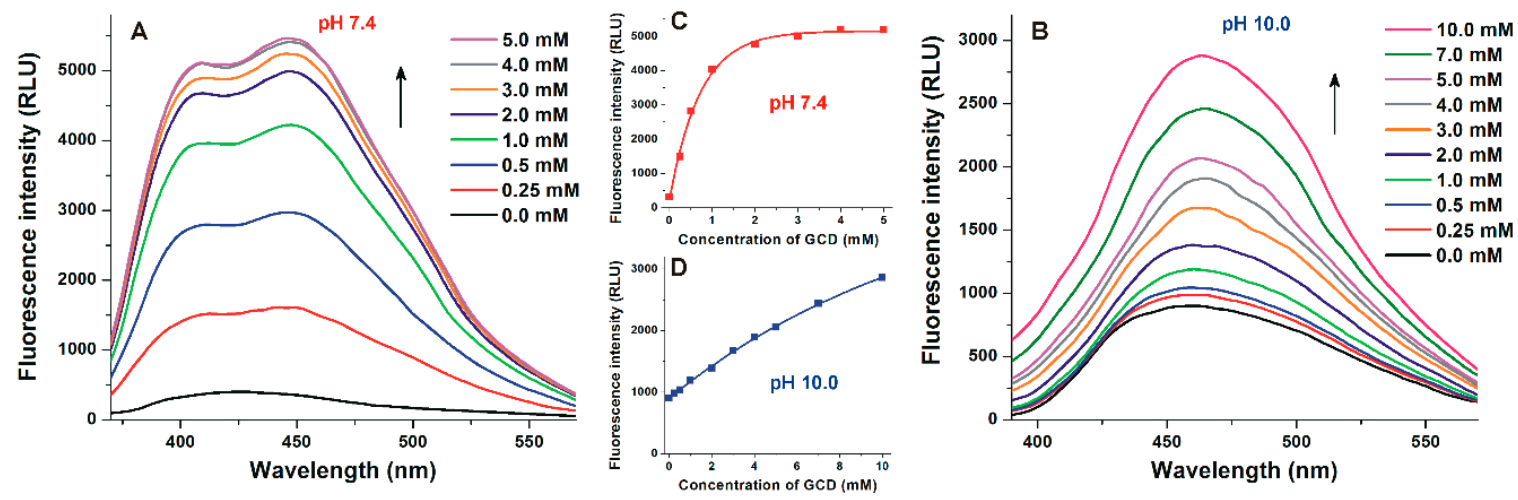

Figure 3. Fluorescence emission spectra of $\mathrm{AOH}(5 \mu \mathrm{M}=1.29 \mathrm{mg} / \mathrm{L})$ in the presence of increasing concentrations of GCD $(0-10 \mathrm{mM})$ in sodium phosphate $(\mathrm{pH} 7.4 ; \mathbf{A})$ and sodium borate $(\mathrm{pH} 10.0 ; \mathbf{B})$ buffers $\left(\lambda_{\mathrm{ex}}=345 \mathrm{~nm}\right)$. GCD-induced increase in the emission signal of $\mathrm{AOH}\left(\lambda_{\mathrm{ex}}=345 \mathrm{~nm}, \lambda_{\mathrm{em}}=\right.$ $460 \mathrm{~nm}$ ) in phosphate ( $\mathrm{pH} 7.4 ; \mathrm{C})$ and borate (pH 10.0; D) buffers (ex slits: $10 \mathrm{~nm}$ at both pH; em slits: 10 and $20 \mathrm{~nm}$ at $\mathrm{pH} 7.4$ and 10.0, respectively; RLU, relative light unit).

The emission spectra of $\mathrm{AOH}$ in the presence of cationic CDs (tetraalkylammonium salts, QABCD and QAGCD) behaved similar to the uncharged CDs at pH 5.0 (Figure 4A) and 10.0 (Figure 4C), while the strong decrease of peak 1 vs. peak 2 was noticed even at pH 7.4 (Figure 4B).

A further typical difference between uncharged and cationic CDs is also demonstrated using GCD and QAGCD as examples. At acidic and physiological pH, GCD induced a strong increase in the fluorescence of $\mathrm{AOH}$ even at $0.25 \mathrm{mM}$ concentration, and the emission signal of $\mathrm{AOH}$ reached its maximum in the presence of $4 \mathrm{mM} \mathrm{GCD}$ (Figure 3A,C). However, at pH 10.0, the emission signal of $\mathrm{AOH}$ only slightly increased by low GCD concentrations $(0.25$ and $0.5 \mathrm{mM})$ and strongly raised (as well as did not reach its plateau) even in the presence of $10 \mathrm{mM}$ GCD (Figure 3B,D). In contrast, increasing concentrations of QAGCD induced a less steep, gradual increase in the fluorescence of $\mathrm{AOH}$ at $\mathrm{pH}$ 5.0 (0.25 and $0.5 \mathrm{mM}$ concentrations of QAGCD produced only slight effects, and the fluorescence signal did not reach a maximum even in the presence of $10 \mathrm{mM}$ QAGCD) (Figure 4A,D). At pH 7.4, a steeper elevation in fluorescence can be observed compared to the acidic environment (Figure 4B,E). Furthermore, at $\mathrm{pH}$ 10.0, QAGCD induced a spectacular increase in the fluorescence of AOH even at low concentration (e.g., $0.25 \mathrm{mM}$ ), and the emission signal of the mycotoxin reached its maximum even in the presence of $3 \mathrm{mM}$ QAGCD (Figure $4 \mathrm{C}, \mathrm{F}$ ). 

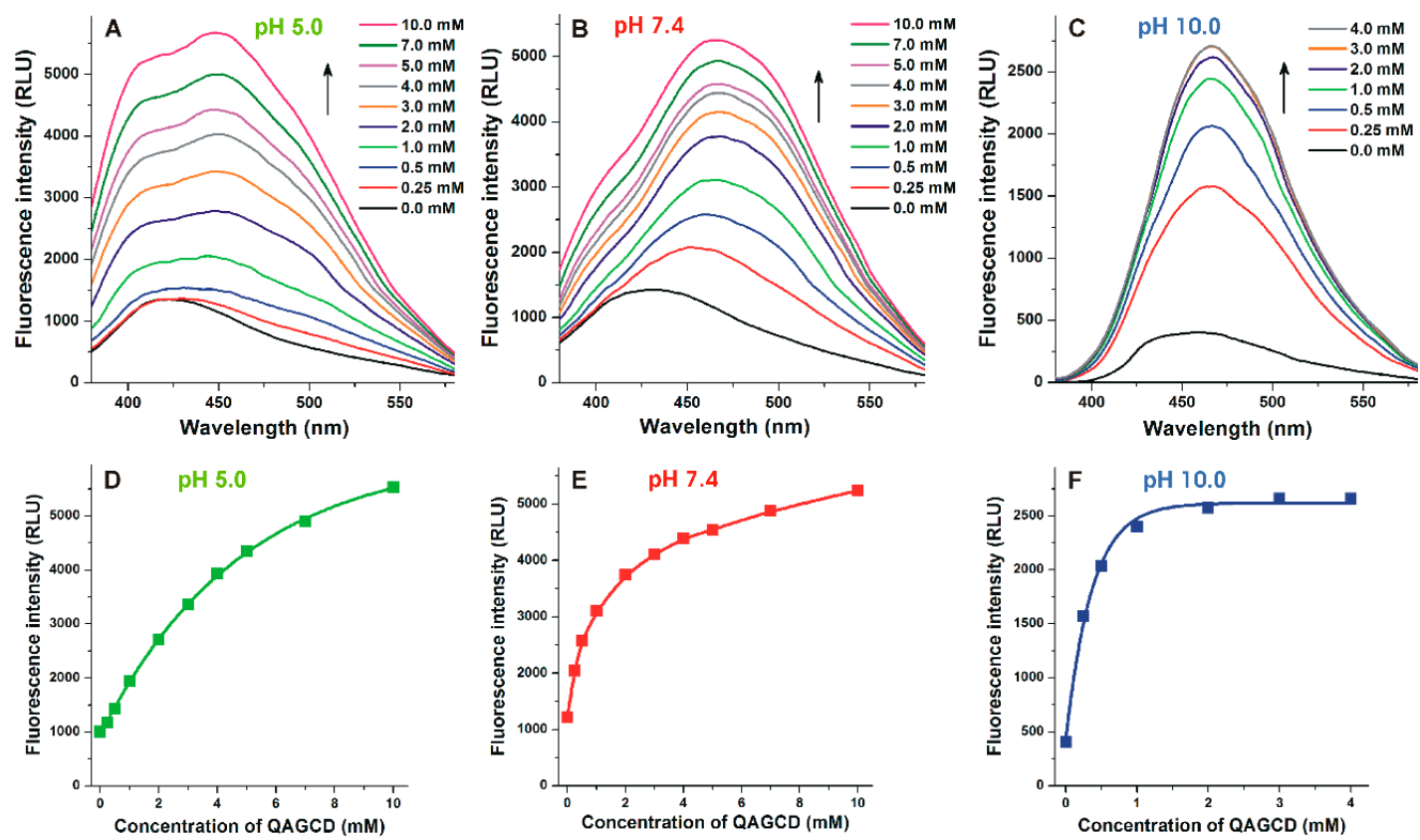

Figure 4. Fluorescence emission spectra of $\mathrm{AOH}(5 \mu \mathrm{M})$ in the presence of increasing concentrations of QAGCD $(0-10 \mathrm{mM})$ in sodium acetate ( $\mathrm{pH} 5.0 ; \mathbf{A})$, sodium phosphate ( $\mathrm{pH} 7.4 ; \mathbf{B})$, and sodium borate $(\mathrm{pH} 10.0 ; \mathrm{C})$ buffers $\left(\lambda_{\mathrm{ex}}=345 \mathrm{~nm}\right)$. QAGCD-induced increase in the emission signal of AOH $\left(\lambda_{\mathrm{ex}}=\right.$ $345 \mathrm{~nm}, \lambda_{\mathrm{em}}=460 \mathrm{~nm}$ ) in acetate (pH 5.0; D), phosphate (pH 7.4; E), and borate (pH 10.0; F) buffers (ex slits: $10 \mathrm{~nm}$ at each $\mathrm{pH}$; em slits: 20, 20, and $10 \mathrm{~nm}$ at $\mathrm{pH}$ 5.0, 7.4, and 10.0, respectively; RLU, relative light unit).

In a concentration-dependent fashion, each $\mathrm{CD}$ tested markedly increased the fluorescence emission signal of $\mathrm{AOH}$ (Figure $5 ; \lambda_{\mathrm{ex}}=345 \mathrm{~nm}, \lambda_{\mathrm{em}}=460 \mathrm{~nm}$ ), except the native $\mathrm{BCD}$, which only slightly enhanced the fluorescence of the mycotoxin (from 1.1- to 2.0-fold increase was observed in the presence of $5 \mu \mathrm{M} \mathrm{AOH}$ and $2.0 \mathrm{mM} \mathrm{BCD}$ ). At $\mathrm{pH} 5.0$ and 7.4, the native GCD proved to be the strongest fluorescence enhancer. However, at $\mathrm{pH}$ 10.0, quaternary ammonium derivatives were the most effective from this point of view, QABCD induced the strongest increase in the emission signal of $\mathrm{AOH}$ (Figure 5).

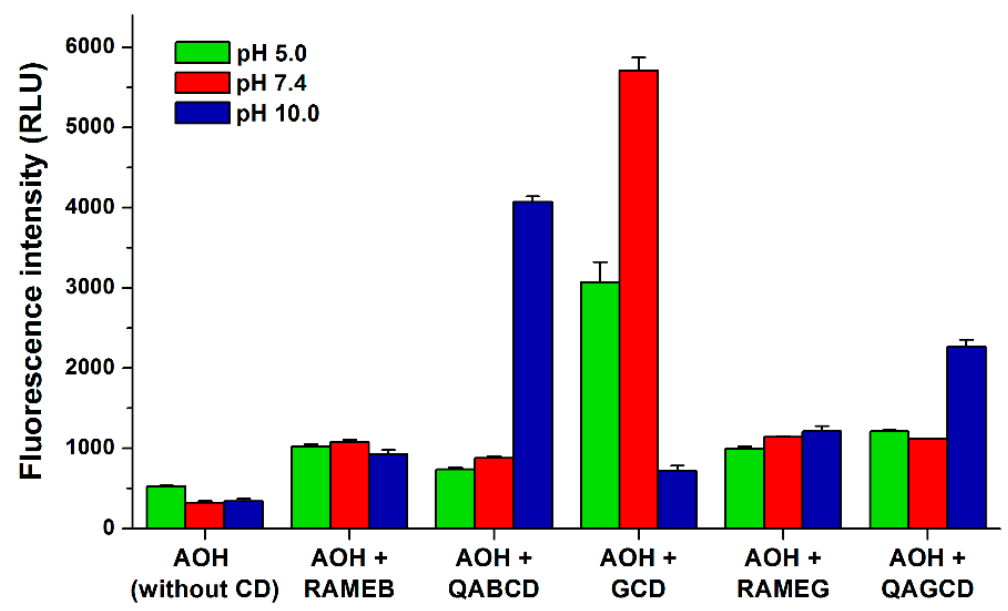

Figure 5. Absolute fluorescence signal $( \pm \mathrm{SEM})$ of $\mathrm{AOH}(5 \mu \mathrm{M})$ in the absence and presence of CDs (10 mM each) in different buffers: sodium acetate (50 mM, pH 5.0), sodium phosphate (50 mM, pH 7.4), and sodium borate ( $50 \mathrm{mM}, \mathrm{pH} 10.0)\left(\lambda_{\mathrm{ex}}=345 \mathrm{~nm}, \lambda_{\mathrm{ex}}=460 \mathrm{~nm}\right.$; ex slit: $10 \mathrm{~nm}$, em slit: $10 \mathrm{~nm}$; RLU, relative light unit). Because of the lower aqueous solubility of BCD vs. other CDs tested, BCD has not been demonstrated here. 


\subsection{Binding Constants of Alternariol-Cyclodextrin Complexes}

Binding constants of $\mathrm{AOH}-\mathrm{CD}$ complexes were determined based on fluorescence emission data employing the graphical application of the Benesi-Hildebrand equation (Equation (1); $\lambda_{\mathrm{ex}}=345 \mathrm{~nm}$, $\lambda_{\mathrm{em}}=460 \mathrm{~nm} ; \log K$ values were also determined using other emission wavelengths to confirm our results). Benesi-Hildebrand plots showed good linearity $\left(R^{2}=0.95-0.99\right)$ with the $1: 1$ stoichiometry model (Figure 6).
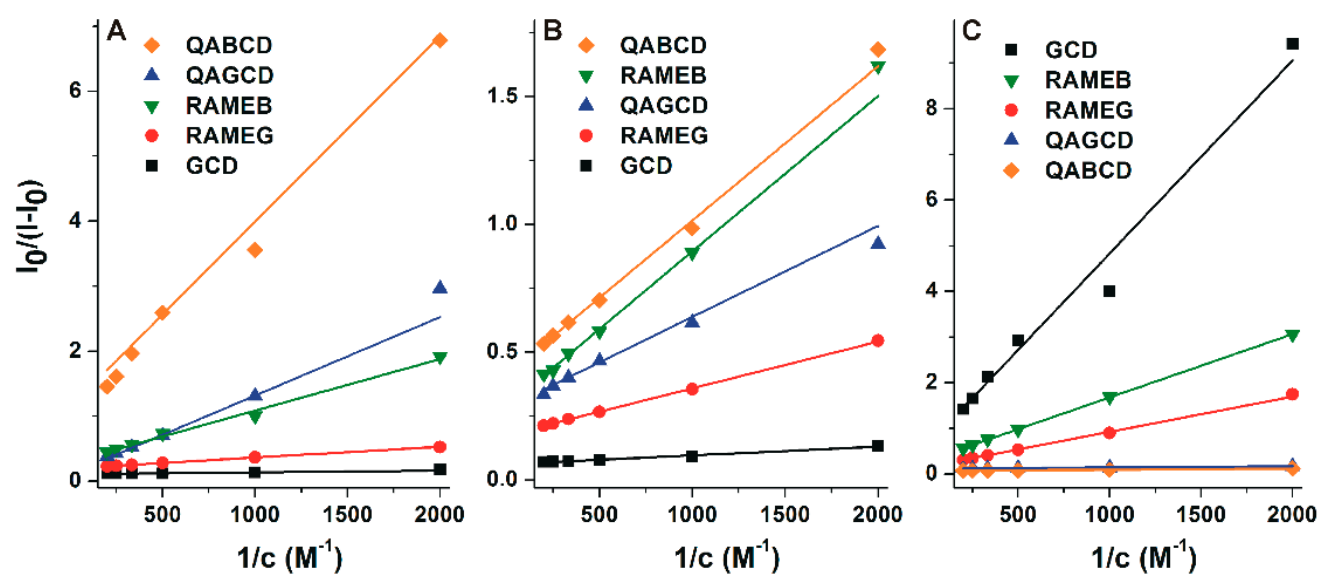

Figure 6. Benesi-Hildebrand plots $\left(\mathrm{R}^{2}=0.95-0.99\right)$ of AOH-CD complexes in different buffers $\left(\lambda_{\mathrm{ex}}=\right.$ $345 \mathrm{~nm}, \lambda_{\mathrm{ex}}=460 \mathrm{~nm}$ ): (A) sodium acetate (50 mM, pH 5.0), (B) sodium phosphate (50 mM, pH 7.4), and (C) sodium borate (50 mM, pH 10.0).

The calculated $\log K$ values of $\mathrm{AOH}-\mathrm{CD}$ complexes are listed in Table 1. Because of the lower aqueous solubility of BCD, its lower concentrations were applied (see Section 2.2). Therefore, the Benesi-Hildebrand plots of $\mathrm{AOH}-\mathrm{BCD}$ complex are demonstrated separately in Figure S2. LogK values were in the range of 2.1-3.6, suggesting the strongly differing stabilities of $\mathrm{AOH}-\mathrm{CD}$ complexes, depending on the $\mathrm{CD}$ applied and the environmental conditions (Table 1). Under acidic and physiological circumstances, the binding constants of RAMEB, GCD, and RAMEG complexes were significantly higher than at $\mathrm{pH}$ 10.0. At $\mathrm{pH} 5.0$ and 7.4, the native GCD formed highly the most stable complexes with the mycotoxin. However, under alkaline circumstances ( $\mathrm{pH} 10.0), \mathrm{AOH}$ bound to the quaternary ammonium derivatives (QABCD and QAGCD) with approximately 10-fold higher affinity than to other CDs tested.

Table 1. Decimal logarithmic values of the binding constants (K; unit: $\mathrm{L} / \mathrm{mol})$ of $\mathrm{AOH}-\mathrm{CD}$ complexes.

\begin{tabular}{cccc}
\hline \multirow{2}{*}{$\begin{array}{c}\text { Mycotoxin-CD } \\
\text { Complex }\end{array}$} & \multicolumn{3}{c}{$\log \boldsymbol{K}( \pm$ SEM $)$} \\
\cline { 2 - 4 } & $\mathbf{p H ~ 5 . 0}$ & $\mathbf{p H ~ 7 . 4}$ & $\mathbf{p H ~ 1 0 . 0}$ \\
\hline AOH-BCD & $2.23 \pm 0.01$ & $2.52 \pm 0.01$ & $2.22 \pm 0.03$ \\
AOH-RAMEB & $2.50 \pm 0.02$ & $2.64 \pm 0.01$ & $2.11 \pm 0.03$ \\
AOH-QABCD & $2.38 \pm 0.03$ & $2.85 \pm 0.04$ & $3.40 \pm 0.01$ \\
AOH-GCD & $3.18 \pm 0.06$ & $3.21 \pm 0.01$ & $2.17 \pm 0.03$ \\
AOH-RAMEG & $2.96 \pm 0.03$ & $3.03 \pm 0.03$ & $2.23 \pm 0.03$ \\
AOH-QAGCD & $2.11 \pm 0.03$ & $2.97 \pm 0.01$ & $3.58 \pm 0.03$
\end{tabular}

Buffers used: sodium acetate (50 mM, pH 5.0), sodium phosphate (50 mM, pH 7.4), and sodium borate (50 mM, pH 10.0). See further details in Section 2.2 and Figure 6.

Since a marked emission peak also appeared around $410 \mathrm{~nm}$ at $\mathrm{pH} 5.0$ regarding each $\mathrm{CD}$ examined (see in Figure 4A), the binding constants were also determined at pH 5.0 using 345 and $410 \mathrm{~nm}$ excitation and emission wavelengths, respectively. The calculated binding constants were same as the data determined applying $460 \mathrm{~nm}$ emission wavelength (see in Table 1). 
To confirm the binding constants and stoichiometry determined based on the Benesi-Hildebrand equation, some data were also evaluated using the graphical application of the Scatchard equation (Equation (2); $\lambda_{\mathrm{ex}}=345 \mathrm{~nm}, \lambda_{\mathrm{em}}=460 \mathrm{~nm}$ ). The Scatchard plot of AOH-GCD complex (at pH 7.4) is demonstrated in Figure S3. This model also showed an excellent correlation with the 1:1 stoichiometry of complex formation, and gave similar binding constants to the evaluation performed with the Benesi-Hildebrand plot (e.g., the $\log K$ values regarding AOH-GCD complex were $3.21 \pm 0.01$ vs. $3.31 \pm 0.05$ based on the Benesi-Hildebrand plot and the Scatchard plot, respectively).

\subsection{Modeling Studies}

To get a deeper insight into the complex formation, the $\mathrm{AOH}$ guest molecule and its deprotonated derivatives with the CD host molecules were investigated. The host molecules were represented by variation of the total molecular charge of the parent BCD and GCD molecules, while the deprotonated guest molecules were represented by their most stable conformers. Accordingly, the most probable deprotonation route of $\mathrm{AOH}$ is determined considering the formation energies associated to each deprotonation step. The differently protonated derivatives of $\mathrm{AOH}$ (Figure 7) were then used to investigate the complex formation. The inclusion of $\mathrm{AOH}$ by the cavities of BCD and GCD is demonstrated in Figure 8. A steric hindrance appeared regarding AOH-BCD interaction, so the mycotoxin is therefore able to sink deeper into the cavity of GCD.
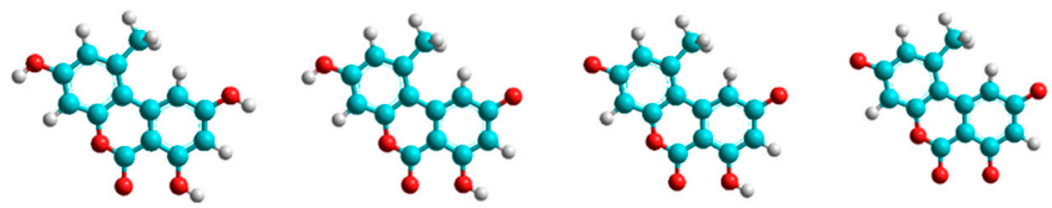

Figure 7. The energetically most favorable deprotonation route of $\mathrm{AOH}$ (from left to right: nonionic $\mathrm{AOH}$, monoanionic $\mathrm{AOH}$, dianionic $\mathrm{AOH}$, and trianionic $\mathrm{AOH}$ ) determined at $\mathrm{AM} 1$ method in the present work $(\mathrm{C}, \mathrm{O}$, and $\mathrm{H}$ atoms are indicated with blue, red, and white spheres, respectively). These results are in agreement with the previous study of Tu and co-workers (calculated at B3LYP using $6-311++\mathrm{G}^{* *}$ basis set) [43].
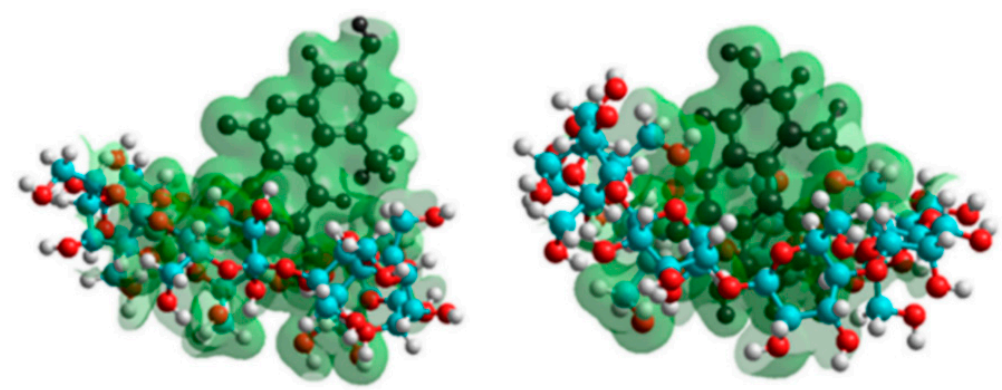

Figure 8. Equilibrium conformation with isosurface charge grids of $\mathrm{AOH}-\mathrm{BCD}$ (left) and AOH-GCD (right) complexes. $\mathrm{C}, \mathrm{O}$, and $\mathrm{H}$ atoms of $\mathrm{BCD}$ and $\mathrm{GCD}$ are indicated with blue, red, and white spheres, respectively; while $\mathrm{AOH}$ is represented by black spheres.

Based on modeling studies, the $\log K$ values associated to the formation of AOH-CD complexes were calculated and are summarized in Table 2. These results support the higher stability of AOH-GCD vs. AOH-BCD complexes and are in agreement with the experimental data (Table 1) according to the tendencies of the protonation state or the electron density of the host cavity. Native and randomly methylated CDs form more stable complexes with the nonionic form of the mycotoxin, while the positively charged quaternary ammonium derivatives prefer the deprotonated forms of $\mathrm{AOH}$. 
Table 2. $\log K$ values (the unit of $K$ is $\mathrm{L} / \mathrm{mol}$ ) of $\mathrm{AOH}-\mathrm{CD}$ complexes based on theoretical calculations. Semi-empirical AM1 method with TIP3P solvation model was applied.

\begin{tabular}{cccccc}
\hline $\begin{array}{c}\text { Host } \\
\text { Molecule }\end{array}$ & $\begin{array}{c}\text { Host } \\
\text { Simulated as }\end{array}$ & $\begin{array}{c}\text { LogK Values of AOH and Its Deprotonated Forms } \\
\text { AOH } \\
\text { (Nonionic) }\end{array}$ & $\begin{array}{c}\text { AOH } \\
\text { (Monoanionic) }\end{array}$ & $\begin{array}{c}\text { AOH } \\
\text { (Dianionic) }\end{array}$ & $\begin{array}{c}\text { AOH } \\
\text { (Trianionic) }\end{array}$ \\
\hline BCD & 0 BCD & 2.61 & 2.51 & 2.46 & 2.42 \\
RAMEB & -1 BCD & 2.52 & 2.41 & 2.32 & 2.14 \\
QABCD & +1 BCD & 2.48 & 2.81 & 2.98 & 3.40 \\
GCD & 0 GCD & 3.17 & 3.11 & 3.04 & 2.61 \\
RAMEG & -1 GCD & 3.11 & 2.87 & 2.72 & 2.46 \\
QAGCD & +1 GCD & 2.29 & 2.88 & 3.12 & 3.46 \\
\hline
\end{tabular}

The methyl derivatives (RAMEB and RAMEG), due to the electron releasing property of methyl substituent, were considered as negatively charged $(-1)$ CDs. The quaternary ammonium derivatives (QABCD and QAGCD), because of the electron withdrawing character of the tetraalkylammonium moiety, were considered as the positively charged $(+1)$ CDs.

\subsection{Extraction of Alternariol from Aqueous Solution by Insoluble $\beta$-Cyclodextrin Bead Polymer}

Since the first acid dissociation constant $\left(\mathrm{pK}_{\mathrm{a}}\right)$ value of $\mathrm{AOH}$ is approximately 8.4 [44], we did not see reasonable to use lower $\mathrm{pH}$ than 5.0 in the previous experiments. However, $\mathrm{AOH}$ commonly appears in more acidic drinks (e.g., wine and tomato juice). Therefore, the removal of AOH by BBP was tested in the $\mathrm{pH}$ range of 3.0-10.0. The standard concentration of $\mathrm{AOH}(2 \mu \mathrm{M}=516.5 \mu \mathrm{g} / \mathrm{L}$, in $1.5 \mathrm{~mL}$ buffer) was incubated in the presence of increasing amounts of BBP $(1.0-20.0 \mathrm{mg} / 1.5 \mathrm{~mL}$; see further details in Section 2.4), then the mycotoxin content of the supernate was quantified by HPLC-FLD (see Section 2.5). In a concentration-dependent fashion, BBP removed significant amounts of AOH from aqueous solutions (Figure 9). Insoluble $\beta$-cyclodextrin bead polymer was similarly effective mycotoxin binder in the 3.0-7.4 $\mathrm{pH}$ range. However, its $\mathrm{AOH}$ binding ability was strongly decreased at $\mathrm{pH} 10.0$ compared to the other buffers applied. Under acidic and weakly alkaline circumstances (pH 3.0-7.4), even low amounts of BBP $(1.0 \mathrm{mg} / 1.5 \mathrm{~mL})$ caused approximately $60 \%$ decrease in the mycotoxin content of the solutions, and $10.0 \mathrm{mg} / 1.5 \mathrm{~mL}$ BBP almost completely removed $\mathrm{AOH}$ (Figure 9). However, at $\mathrm{pH}$ 10.0 , only 47 and $66 \%$ decrease in the $\mathrm{AOH}$ content of the supernatant was observed in the presence of 10.0 and $20.0 \mathrm{mg} / 1.5 \mathrm{~mL}$ BBP, respectively.

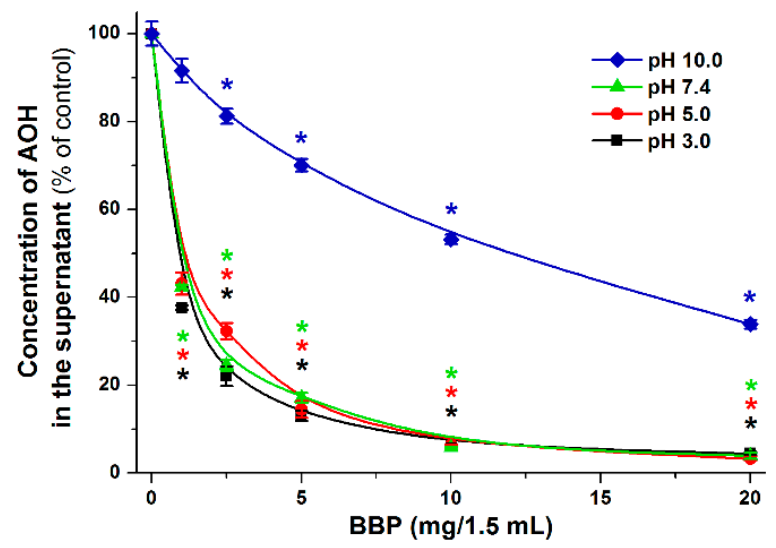

Figure 9. Extraction of $\mathrm{AOH}$ from aqueous solutions by insoluble $\beta$-cyclodextrin bead polymer (BBP). Effects of increasing concentrations of $\operatorname{BBP}(0.0,1.0,2.5,5.0,10.0$, and $20.0 \mathrm{mg} / 1.5 \mathrm{~mL})$ on the $\mathrm{AOH}$ (initial concentration: $2 \mu \mathrm{M}$ ) content of different buffers ( $50 \mathrm{mM}$ sodium phosphate, $\mathrm{pH} 3.0 ; 50 \mathrm{mM}$ sodium acetate, $\mathrm{pH}$ 5.0; $50 \mathrm{mM}$ sodium phosphate, $\mathrm{pH} 7.4$; and $50 \mathrm{mM}$ sodium borate, $\mathrm{pH}$ 10.0). Incubations were carried out in a thermomixer $\left(1000 \mathrm{rpm}, 30 \mathrm{~min}, 25^{\circ} \mathrm{C} ;{ }^{*} p<0.01\right)$.

To quantitatively characterize the $\mathrm{AOH}$ binding ability of $\mathrm{BBP}$, increasing $\mathrm{AOH}$ concentrations $(0.2-15 \mu \mathrm{M}$ in $1.5 \mathrm{~mL}$ buffer $)$ were added to standard amount of BBP $(2.5 \mathrm{mg})$ in sodium phosphate buffer 
(pH 3.0). Figure 10 demonstrates the corresponding Langmuir and Freundlich isotherms. Experimental data showed good fitting with both Langmuir (Equation (4)) and Freundlich (Equation (5)) models $\left(\mathrm{R}^{2}=0.98\right.$ and 0.97 , respectively). The Langmuir equilibrium constant $\left(K_{L}\right)$ was $0.16 \pm 0.04 \mathrm{~L} / \mathrm{mg}$, and the maximum quantity of $\mathrm{AOH}(\mathrm{mg})$ bound per gram of BBP $\left(Q_{0}\right.$ value) was $41.92 \pm 3.94 \mathrm{mg} / \mathrm{g}$. Furthermore, the Freundlich constant $\left(K_{F}\right)$ was $5.52 \pm 1.31(\mathrm{mg} / \mathrm{g}) \times(\mathrm{L} / \mathrm{mg})^{1 / \mathrm{n}}$, while the $1 / \mathrm{n}$ value was $0.74 \pm 0.04$.

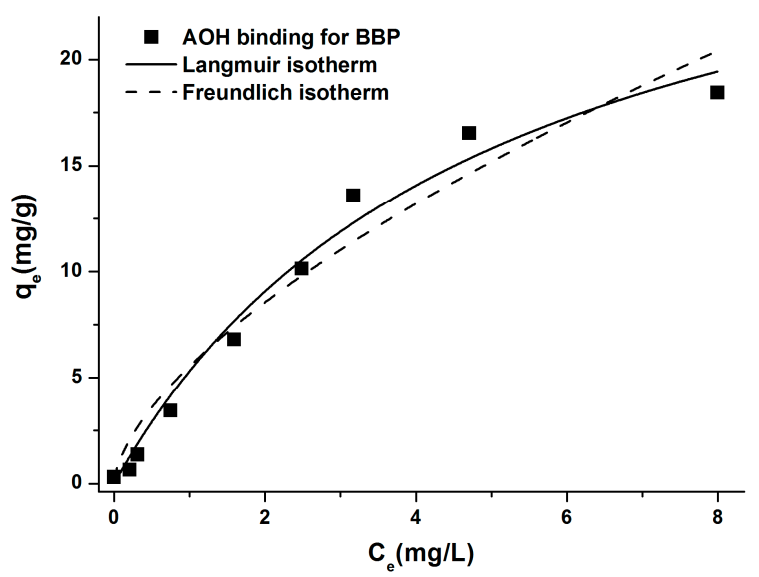

Figure 10. Langmuir (solid line) and Freundlich (dashed line) isotherms for the AOH binding of BBP in sodium phosphate buffer $(50 \mathrm{mM}, \mathrm{pH} 3.0)$. The amount of bound $\mathrm{AOH}(\mathrm{mg})$ by BBP $(\mathrm{g})$ and the amount of unbound $\mathrm{AOH}(\mathrm{mg})$ in the solution at equilibrium are indicated by $q_{e}$ and $C_{e}$, respectively.

3.6. Comparison of the Interactions of Alternariol with Native $\beta$-Cyclodextrin, Soluble $\beta$-Cyclodextrin Polymer, and Insoluble $\beta$-Cyclodextrin Bead Polymer

Despite the stability of AOH-BCD complex is relatively low (Table 1), BBP very effectively decreased the mycotoxin content of aqueous solution (Figure 9). To test the hypothesis that BCD polymers may have considerably higher $\mathrm{AOH}$ binding capacity compared to the native BCD, the $\mathrm{AOH}$ binding ability of BCD, soluble BCD polymer, and BBP were compared in the same buffer (sodium phosphate, $\mathrm{pH}$ 3.0). Increasing amounts of BCD and soluble BCD polymer were added to $\mathrm{AOH}(2 \mu \mathrm{M})$, and then fluorescence emission spectra were recorded. According to the manufacturer's description, the soluble BCD polymer and the BBP contains approximately 70 and $50 \mathrm{~m} / \mathrm{m} \%$ BCD, respectively. Based on these data, $\mathrm{BCD}$ concentrations contained by the applied amounts of soluble $\mathrm{BCD}$ polymer and BBP were calculated. The relative increase in the fluorescence emission signal of $\mathrm{AOH}\left(\mathrm{I} / \mathrm{I}_{0}\right)$ in the presence of $\mathrm{BCD}$ and soluble BCD polymer was plotted as a function of the BCD concentration (Figure 11A,B). Similarly, the bound fraction of AOH in the presence of BBP (calculated based on the data represented in Figure 9) was also plotted vs. the BCD concentration contained by BBP (Figure 11C). Under the applied conditions, BCD induced less than $10 \%$ increase in the emission signal of $\mathrm{AOH}$, while soluble BCD polymer caused more than five-fold enhancement in the fluorescence of the mycotoxin (Figure 11A,B). $\beta$-cyclodextrin polymers which are equivalent to $1.5-2.0 \mathrm{mM}$ BCD content were able to bind close the total amount of $\mathrm{AOH}$ molecules (Figure 11A,B). However, the curve of BCD was far from the saturation even in the presence of $2.5 \mathrm{mM} B C D$ (Figure 11A). Binding constants were quantified using the Benesi-Hildebrand equation (Equation (1); for BCD and soluble $\mathrm{BCD}$ polymer) and based on the free and bound fractions of $\mathrm{AOH}$ and BBP (Equation (7); for BBP), assuming 1:1 stoichiometry of complex formation (see details in Section 2.6). LogK values were 2.40 $( \pm 0.07), 3.40( \pm 0.01)$, and $3.67( \pm 0.07)$ regarding BCD, soluble BCD polymer, and BBP, respectively. 

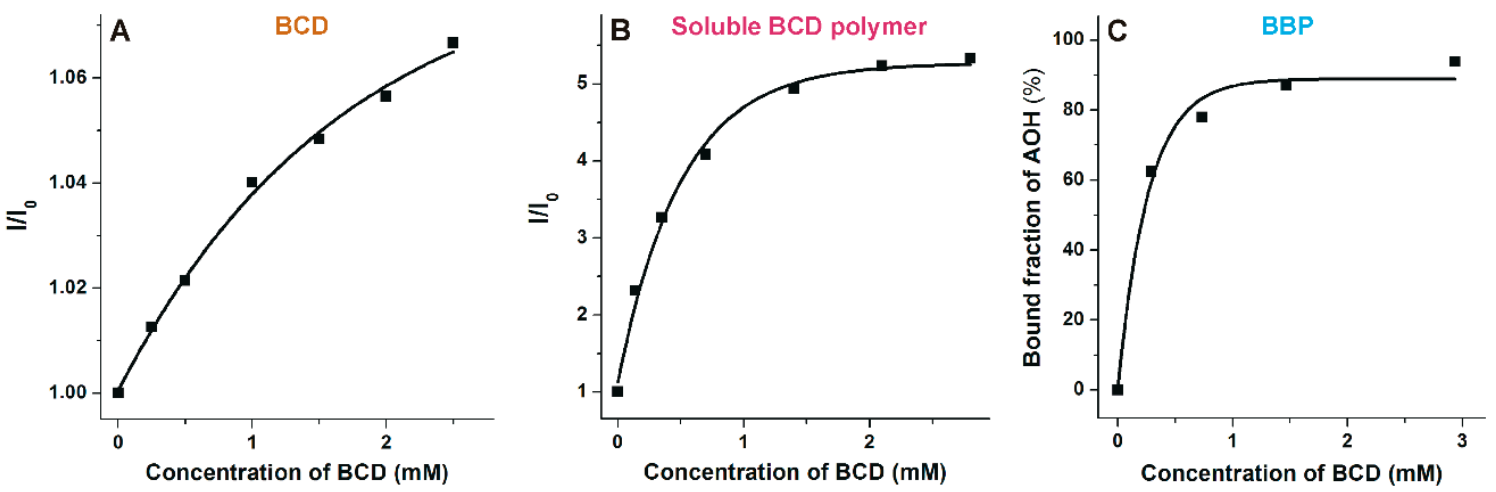

Figure 11. Comparison of the interactions of $\mathrm{AOH}$ with $\mathrm{BCD}$, soluble $\mathrm{BCD}$ polymer, and BBP. Relative increase $\left(\mathrm{I} / \mathrm{I}_{0}\right)$ in the fluorescence emission intensity of $\mathrm{AOH}$ in the presence of increasing concentrations of $\mathrm{BCD}\left(\mathrm{A} ; \lambda_{\mathrm{ex}}=345 \mathrm{~nm}, \lambda_{\mathrm{ex}}=460 \mathrm{~nm}\right)$. Relative increase $\left(\mathrm{I} / \mathrm{I}_{0}\right)$ in the fluorescence emission intensity of $\mathrm{AOH}$ in the presence of increasing concentrations of soluble BCD polymer $\left(\mathbf{B} ; \lambda_{\mathrm{ex}}=345 \mathrm{~nm}, \lambda_{\mathrm{ex}}=460 \mathrm{~nm}\right.$; concentration of $\mathrm{BCD}$ represents the molar $\mathrm{BCD}$ content of the applied amount of the soluble polymer). Bound fraction of $\mathrm{AOH}$ (\% of total $\mathrm{AOH}$ concentration; calculated based on the data demonstrated in Figure 9) in the presence of increasing concentrations of BBP (C; concentration of BCD represents the molar BCD content of the applied amount of BBP). Each experiment was performed with $2 \mu \mathrm{M} \mathrm{AOH}$ concentration in sodium phosphate buffer (50 mM, pH 3.0).

\section{Discussion}

$\mathrm{AOH}$ possesses three phenolic hydroxyl groups (Figure 1). Considering the previously reported $\mathrm{pK}_{\mathrm{a}}$ values of $\mathrm{AOH}(8.4,9.7$, and 13.6) [44], it appears dominantly in its nonionic form (each phenolic hydroxyl group of the mycotoxin is protonated) at $\mathrm{pH}$ 5.0. With the elevation of the $\mathrm{pH}$, significant changes in the fluorescence excitation and emission spectra of $\mathrm{AOH}$ were observed (Figure 2 and Figure S1), likely due to the deprotonation of the mycotoxin. In the applied $\mathrm{pH}$ range, the nonionic, monoanionic, and dianionic forms of the mycotoxin appear at relevant concentrations. Unfortunately, we cannot see separately the fluorescence spectra of the ionized forms because both monoanionic and dianionic $\mathrm{AOH}$ gradually appear with the elevation of the $\mathrm{pH}$. Two distinct peaks were noticed in the excitation spectra of $\mathrm{AOH}$ (approximately at 350 and $410 \mathrm{~nm}$; see in Figure 2A,B). The lack of the second peak at $\mathrm{pH} 5.0$ and its appearance at higher $\mathrm{pH}$ values $(\mathrm{pH} 7.4$ and 10.0) suggest that the higher excitation peak (at $410 \mathrm{~nm}$ ) belongs to the ionized forms of the mycotoxin. This hypothesis is also supported by the emission spectra recorded using $410 \mathrm{~nm}$ excitation wavelength: no significant emission was noticed at $\mathrm{pH}$ 5.0, while an increasing emission peak appeared at higher $\mathrm{pH}$ values applied (Figure S1A). Furthermore, with the elevation of the $\mathrm{pH}$, the first excitation peak (around $350 \mathrm{~nm}$ ) decreased but did not disappear (Figure 2A,B). Thus, the first excitation peak can also be applied during the investigation of the ionized mycotoxins (at least monoanionic AOH). This hypothesis is also supported by the observation that significant emission signal of the mycotoxin was noticed using $345 \mathrm{~nm}$ excitation wavelength, even at $\mathrm{pH} 10.0$ (Figure 2C).

Using $345 \mathrm{~nm}$ excitation wavelength, the emission spectrum of $\mathrm{AOH}$ seems to be one wide peak (Figure 2C). However, in the presence of CDs, we can distinguish two emission peaks (around 410 and $460 \mathrm{~nm}$ ) at pH 5.0 and 7.4 (Figures 3 and 4). Since AOH has tautomers [43], these two peaks likely belong to the two tautomeric forms of nonionic $\mathrm{AOH}$. The tautomers can be visibly distinguished only in the presence of CDs, as it has also been reported regarding flavonoids fisetin and geraldol [45]. Log K values of $\mathrm{AOH}-\mathrm{CD}$ complexes were determined at $\mathrm{pH} 5.0$ using both 410 and $460 \mathrm{~nm}$ emission wavelengths, during which the calculated binding constants were identical. Based on these data, the tautomers of nonionic $\mathrm{AOH}$ bind to the same $\mathrm{CD}$ with the same affinity. With the elevation of the $\mathrm{pH}$, the first emission peak became less dominant and/or disappeared at $\mathrm{pH}$ 10.0. Cationic CDs tested (QABCD and QAGCD) induced the strong decrease of the emission peak at $410 \mathrm{~nm}$ even at $\mathrm{pH} 7.4$ (Figure 4), while it was not observed with other CDs (BCD, RAMEB, GCD, and RAMEG) (Figure 3). 
These observations support that the emission peak at $410 \mathrm{~nm}$ belongs to the nonionic $\mathrm{AOH}$. Since quaternary ammonium derivatives form more stable complexes with the ionized form(s) of $\mathrm{AOH}$ (Tables 1 and 2), QABCD and QAGCD can shift the chemical equilibrium toward the deprotonation of the mycotoxin, which consequently leads to the decreased emission peak at $410 \mathrm{~nm}$.

GCD and QABCD induced a more than ten-fold increase in the fluorescence of $\mathrm{AOH}$ at $\mathrm{pH} 7.4$ and 10.0, respectively. Cyclodextrins have been widely used to increase the performance and sensitivity of analytical techniques, including mycotoxin analysis [32,33,46]. Previous studies demonstrated that the fluorescence intensity of fluorescent mycotoxins can be strongly increased as a result of the formation of mycotoxin-CD host-guest type complexes $[29,33,42,47]$. It can be explained by the fact that water molecules can significantly quench the fluorescence of aromatic fluorophores [48]. Since the inclusion of the mycotoxin by the apolar CD cavity disrupts the hydration shell of the mycotoxin, the quenching effect of water molecules decreases, and consequently the increased fluorescence signal of $\mathrm{AOH}$ can be observed [27,41,42]. As the modeling studies suggest, non-ionized AOH sinks deeper into the GCD than into the BCD cavity (Figure 8). Therefore, the greater part of the fluorophore is protected from the external quencher molecules, which may explain the stronger enhancement in the fluorescence of $\mathrm{AOH}$ in the presence of GCD vs. BCD. Furthermore, at $\mathrm{pH} 10.0$, the electrostatic interaction between the anionic form(s) of $\mathrm{AOH}$ and the positively charged quaternary ammonium $\mathrm{CDs}$ can increase the steric hindrance of $\mathrm{AOH}$ [49], leading to the strong increase in the fluorescence of the mycotoxin.

The stability of AOH-CD complexes was highly influenced by the environmental $\mathrm{pH}$ and by the CD applied (Table 1). At pH 10.0, QAGCD formed the most stable complex with the mycotoxin, while at $\mathrm{pH} 5.0$ and 7.4, GCD formed the most stable complexes with the mycotoxin. The interaction of $\mathrm{AOH}$ with $\mathrm{BCD}$ was poorly affected by the $\mathrm{pH}$. The binding constants of AOH-RAMEB, AOH-RAMEG, and AOH-GCD complexes were significantly higher at $\mathrm{pH} 5.0$ and 7.4 (three-, six-, and 10-fold, respectively) vs. at $\mathrm{pH}$ 10.0. However, the stability of AOH-QABCD (three-fold at $\mathrm{pH} 7.4$ and 10-fold at $\mathrm{pH} 10.0$ compared to at $\mathrm{pH}$ 5.0) and AOH-QAGCD (seven-fold at $\mathrm{pH} 7.4$ and 30-fold at $\mathrm{pH} 10.0$ compared to at $\mathrm{pH}$ 5.0) complexes gradually increased with the elevation of the $\mathrm{pH}$. Since at $\mathrm{pH} 10.0$ the monoanionic and dianionic forms of $\mathrm{AOH}$ are dominant, these observations suggest that uncharged CDs generally prefer the nonionic form of $\mathrm{AOH}$, while quaternary ammonium derivatives bind to the anionic form(s) of the mycotoxin with much higher affinity. Because QABCD and QAGCD are positively charged tetraalkylammonium cations, it is reasonable to hypothesize the ionic interaction between these $\mathrm{CDs}$ and $\mathrm{AOH}$ anion(s). Besides the inclusion, an electrostatic interaction contributes to the strong binding between the deprotonated $\mathrm{AOH}$ and the positively charged cavity entrance of $\gamma$-CD torus. It seems a close structural and functional analogy to rocuronium-Sugammadex interaction, where the aminosteroid non-depolarizing muscle relaxant guest binds with high affinity to the anionic $\gamma-C D$ derivative [50]. The deprotonation of the $\mathrm{AOH}$ causes its negatively charged state, which is enhanced by the elevating $\mathrm{pH}$. Modeling studies highlighted that this charge interacts with the host cavity and the electron density of the host molecule moderates the secondary host-guest interactions by the coulomb repulsion (RAMEB, RAMEG) or coulomb attraction (QABCD, QAGCD). As a result, the stability of $\mathrm{AOH}-\mathrm{QABCD}$ and $\mathrm{AOH}-\mathrm{QAGCD}$ complexes is increased by the deprotonation of AOH. In contrast, the opposite tendency was observed with AOH-RAMEB and AOH-RAMEG complexes. The slightly electron rich character of the GCD cavity causes reduced stability at higher deprotonated state of AOH. Overall, higher complex stabilities were observed with $\gamma$-CDs than with $\beta$-CDs in both spectroscopic (Table 1) and modeling (Table 2) studies, which is probably resulted from the steric hindrance appeared during the interactions with the smaller $\mathrm{BCD}$ cavity. Therefore, the entry of $\mathrm{AOH}$ molecule into the host cavity is deeper during the formation of AOH-GCD vs. AOH-BCD complexes (Figure 8).

Data showed good fitting to the 1:1 stoichiometry models regarding both Benesi-Hildebrand (Figure 6) and Scatchard plots (Figure S3), suggesting the 1:1 stoichiometry of complex formation. Furthermore, modeling studies also predicted the formation of 1:1 complexes. Despite the fact that GCD has a large cavity size (which theoretically makes possible the inclusion of more than one guest molecules), the deep inclusion of nonionic $\mathrm{AOH}$ inhibits the accommodation of another guest molecule 
due to the steric hindering. In each other case, when $\mathrm{AOH}$ is presented in its anionic form(s), the repulsive interaction between $\mathrm{AOH}$ molecules also prevents the formation of $\mathrm{AOH}-\mathrm{GCD}$ complexes with higher stoichiometry.

The occurrence of mycotoxins in foods, feeds, and beverages is a considerable health and economic hazard worldwide. To reduce the mycotoxin content of these products, decontamination strategies are extensively studied, including filtration, heat treatment, ultraviolet radiation, addition of chemical reagents or adsorbents, etc. [51-54]. Insoluble CD polymers have been tested in few studies for decontamination/extraction purposes: they were successfully applied for the removal of patulin from apple juice [34,35], zearalenone from corn beer [37], and ochratoxin A from red wine [36]. Furthermore, CDs can also entrap the masked mycotoxin zearalenone-14-O- $\beta$-D-glucoside. BBP significantly reduced the zearalenone-14-O- $\beta$-D-glucoside content of aqueous solution [55]. Despite AOH-BCD complex showed similar binding constant in the $\mathrm{pH}$ range tested ( $\mathrm{pH}$ 3.0-10.0; see in Sections 3.3 and 3.6), BBP proved to be a less effective mycotoxin binder at $\mathrm{pH} 10.0$ compared to other conditions examined ( $\mathrm{pH}$ 3.0-7.4). The extraction of zearalenone by BBP was examined in our previous study under similar experimental conditions. AOH and zearalenone were removed from aqueous solutions by BBP with similar efficiency [37]. The successful extraction of AOH by BBP under acidic circumstances suggests the potential suitability of insoluble $\mathrm{CD}$ polymers regarding the decontamination of acidic beverages like wines ( $\mathrm{pH} \sim 3.1-3.9$ [56]) and tomato juice ( $\mathrm{pH} \sim 4.0-4.2$ [57]), beverages that are frequently contaminated with Alternaria mycotoxins [9,10].

The sorption isotherms can quantitatively describe the mycotoxin binding ability of BBP. Langmuir isotherm describes strictly homogenous monolayer adsorption, while Freundlich model does not have this restriction [58]. The Langmuir equilibrium constants of the interactions of $\mathrm{AOH}$ and zearalenone with $\mathrm{BBP}$ were in the same range $\left(0.16\right.$ and $0.6 \mathrm{~L} / \mathrm{mg}$, respectively), while $Q_{0}$ value (describing the maximum quantity of the mycotoxin bound per gram of BBP) was significantly higher for $\mathrm{AOH}$ (42 vs. $3 \mathrm{mg} / \mathrm{g}$ ) [37]. The Freundlich constant suggests the higher adsorptive capacity of BBP regarding AOH compared to zearalenone $\left(5.5\right.$ and $1.2(\mathrm{mg} / \mathrm{g}) \times(\mathrm{L} / \mathrm{mg})^{1 / \mathrm{n}}$, respectively) [37]. The heterogeneity index $(n)$ for $\mathrm{AOH}-\mathrm{BBP}$ interaction is close to 1, suggesting the relatively homogenous sorption of $\mathrm{AOH}$ by BBP.

The observation that $\mathrm{AOH}$ was removed from aqueous solutions by BBP with similar efficiency to zearalenone [37] was unexpected because $\mathrm{AOH}$ binds to $\mathrm{BCD}$ with considerably lower affinity compared to zearalenone (the $\log K$ values of $\mathrm{AOH}-\mathrm{BCD}$ and zearalenone-BCD complexes are 2.2 and 4.0 at $\mathrm{pH}$ 5.0, respectively) [59]. As it is described in Section 3.6, both soluble BCD polymer and BBP were able to bind $\mathrm{AOH}$ with considerably higher efficiency than it was expected considering their $\mathrm{BCD}$ content. The calculated $\log K$ values listed in Section 3.6 do not describe precisely the interaction of $\mathrm{AOH}$ with $\mathrm{CD}$ polymers (because their BCD content was considered as BCD monomers). Nevertheless, these data clearly demonstrate the higher binding capacity of $B C D$ polymers vs. the BCD monomer. The complexing potency of epichlorohydrin cross-linked BCD polymers sometimes surpasses that of the corresponding monomer (BCD) [60-63]. This phenomenon resulted from the cooperative/synergistic interaction of neighboring $\mathrm{CD}$ units, leading to the improved entrapment/complexing properties of the covalently linked rings [60,63]. Moreover, cross-linked CDs can be considered as partially and statistically dihydroxypropylated CD ethers (Figure S4), which show improved water solubility at room temperature (the disturbed H-bond system on the secondary face of the cavity entrance commonly enhances the aqueous solubility). The better solubility of BCD polymers (vs. BCD) and the cooperating lipophilic cavities, as well as the flexibly cross-linked CD network, support the more effective encapsulation and the more stable interaction with poorly water-soluble bulky guest molecules, such as $\mathrm{AOH}$.

\section{Conclusions}

In summary, the interaction of mycotoxin $\mathrm{AOH}$ was examined with $\mathrm{CDs}$ and $\mathrm{CD}$ polymers. Most of the $\mathrm{CDs}$ induced a strong increase in the fluorescence signal of $\mathrm{AOH}$. The native $\gamma$-CD proved to be the most successful fluorescence enhancer among the $\beta$ - and $\gamma$-CDs tested, resulting in approximately 
15-fold increase in the emission signal of $\mathrm{AOH}$ at $\mathrm{pH}$ 7.4. Native and methyl-substituted CDs formed more stable complexes with the nonionic form of the mycotoxin (under acidic and physiological conditions), while the quaternary ammonium derivatives prefer the ionized form(s) of $\mathrm{AOH}$ (which appear under alkaline circumstances). BBP successfully removed $\mathrm{AOH}$ from aqueous solutions under acidic and close to neutral conditions, but it was a less effective mycotoxin binder at $\mathrm{pH}$ 10.0. The AOH binding ability of soluble BCD polymer and BBP was significantly higher than expected based on their BCD content, suggesting the cooperative/synergistic interaction of neighboring CD units in the polymers applied. Based on the above-listed observations, CD technology seems a promising tool to improve the sensitivity of the fluorescence detection of $\mathrm{AOH}$. Furthermore, $\mathrm{CD}$ polymers may be suitable for the development of new mycotoxin binders to remove $\mathrm{AOH}$ from contaminated beverages and consequently to decrease mycotoxin exposure.

Supplementary Materials: The following are available online at http://www.mdpi.com/2218-273X/9/9/428/s1, Figure S1: Emission spectra of AOH using $410 \mathrm{~nm}$ excitation wavelength, Figure S2: Investigation of AOH-BCD complex formation based on the Benesi-Hildebrand equation (Equation (1)). Figure S3: Investigation of AOH-GCD complex formation based on the Scatchard equation (Equation (2)). Figure S4: Schematic representation of the chemical structure of epichlorohydrin cross-linked BCD polymer.

Author Contributions: Conceptualization, L.S. and M.P.; Formal analysis, E.F.-N., B.L., and S.K.-M.; Funding acquisition, M.P.; Investigation, E.F.-N., B.L., S.K-M., and M.P.; Methodology, E.F.-N. and S.K.-M.; Writing-original draft, E.F-N., S.K.-M., and M.P. Briefly, M.P. and L.S. conceived the study. E.F.-N., M.P., and S.K.-M. wrote the paper. E.F.-N. performed fluorescence spectroscopic studies, mycotoxin extraction experiments, and HPLC analyses. B.L. evaluated the mycotoxin-binding by BBP based on Langmuir and Freundlich isotherms. S.K.-M. carried out molecular modeling studies. All authors have read, edited, and approved the final version of the paper.

Funding: The project was supported by the Hungarian National Research, Development and Innovation Office (FK125166) (M.P. and E.F.-N.). This work was supported by the GINOP-2.3.2-15-2016-00049 grant (S.K.-M.).

Acknowledgments: The authors thank Ákos Szabó for his excellent assistance in the experimental work. This project was supported by the János Bolyai Research Scholarship of the Hungarian Academy of Sciences (M.P.).

Conflicts of Interest: The authors declare no conflict of interest.

\section{References}

1. Arcella, D.; Eskola, M.; Ruiz, J.A.G. Dietary exposure assessment to Alternaria toxins in the European population. EFSA J. 2016, 14, 4654.

2. Scott, P.M.; Lawrence, G.A.; Lau, B.P.Y. Analysis of wines, grape juices and cranberry juices for Alternaria toxins. Mycotoxin Res. 2006, 22, 142-147. [CrossRef] [PubMed]

3. Stratakou, I.; Van Der Fels-Klerx, H.J. Mycotoxins in grapes and wine in Europe: Occurrence, factors affecting the occurrence and related toxicological effects. World Mycotoxin J. 2010, 3, 283-300. [CrossRef]

4. Escrivá, L.; Oueslati, S.; Font, G.; Manyes, L. Alternaria Mycotoxins in Food and Feed: An Overview. J. Food Qual. 2017, 2017,1-20. [CrossRef]

5. Patriarca, A. Alternaria in food products. Curr. Opin. Food Sci. 2016, 11, 1-9. [CrossRef]

6. EFSA. European Food Safety Authority: Scientific Opinion on the risks for animal and public health related to the presence of Alternaria toxins in feed and food. EFSA J. 2011, 9, 2407. [CrossRef]

7. Janić Hajnal, E.; Čolović, R.; Pezo, L.; Orčić, D.; Vukmirović, Đ.; Mastilović, J. Possibility of Alternaria toxins reduction by extrusion processing of whole wheat flour. Food Chem. 2016, 213, 784-790. [CrossRef]

8. Delgado, T.; Gómez-Cordovés, C.; Scott, P. Determination of alternariol and alternariol methyl ether in apple juice using solid-phase extraction and high-performance liquid chromatography. J. Chromatogr. A 1996, 731, 109-114. [CrossRef]

9. Fan, C.; Cao, X.; Liu, M.; Wang, W. Determination of Alternaria mycotoxins in wine and juice using ionic liquid modified countercurrent chromatography as a pretreatment method followed by high-performance liquid chromatography. J. Chromatogr. A 2016, 1436, 133-140. [CrossRef]

10. Fente, C.A.; Jaimez, J.; Vázquez, B.I.; Franco, C.M.; Cepeda, A. Determination of alternariol in tomato paste using solid phase extraction and high-performance liquid chromatography with fluorescence detectiont. Anal. 1998, 123, 2277-2280. [CrossRef] 
11. Asam, S.; Konitzer, K.; Rychlik, M. Precise determination of the Alternaria mycotoxins alternariol and alternariol monomethyl ether in cereal, fruit and vegetable products using stable isotope dilution assays. Mycotoxin Res. 2011, 27, 23-28. [CrossRef] [PubMed]

12. Fliszár-Nyúl, E.; Lemli, B.; Kunsági-Máté, S.; Dellafiora, L.; Dall'Asta, C.; Cruciani, G.; Pethő, G.; Poór, M. Interaction of Mycotoxin Alternariol with Serum Albumin. Int. J. Mol. Sci. 2019, 20, 2352. [CrossRef] [PubMed]

13. Del Valle, E.M.M. Cyclodextrins and their uses: A review. Process Biochem. 2004, 39, 1033-1046. [CrossRef]

14. Kurkov, S.V.; Loftsson, T. Cyclodextrins. Int. J. Pharm. 2013, 453, 167-180. [CrossRef] [PubMed]

15. Loftsson, T.; Duchêne, D. Cyclodextrins and their pharmaceutical applications. Int. J. Pharm. 2007, 329, 1-11. [CrossRef] [PubMed]

16. Poór, M.; Zand, A.; Szente, L.; Lemli, B.; Kunsági-Máté, S. Interaction of $\alpha$ - and $\beta$-zearalenols with $\beta$-cyclodextrins. Molecules 2017, 22, 1910. [CrossRef] [PubMed]

17. Bekers, O.; Uijtendaal, E.V.; Beijnen, J.H.; Bult, A.; Underberg, W.J.M. Cyclodextrins in the Pharmaceutical Field. Drug Dev. Ind. Pharm. 1991, 17, 1503-1549. [CrossRef]

18. Jansook, P.; Ogawa, N.; Loftsson, T. Cyclodextrins: Structure, physicochemical properties and pharmaceutical applications. Int. J. Pharm. 2018, 535, 272-284. [CrossRef]

19. Buschmann, H.-J.; Schollmeyer, E. Applications of cyclodextrins in cosmetic products: A review. J. Cosmet. Sci. 2002, 53, 185-191.

20. Cravotto, G.; Binello, A.; Baranelli, E.; Carraro, P.; Trotta, F. Cyclodextrins as Food Additives and in Food Processing. Curr. Nutr. Food Sci. 2006, 2, 343-350. [CrossRef]

21. Astray, G.; Gonzalez-Barreiro, C.; Mejuto, J.C.; Rial-Otero, R.; Simal-Gándara, J. A review on the use of cyclodextrins in foods. Food Hydrocoll. 2009, 23, 1631-1640. [CrossRef]

22. Loftsson, T.; Brewster, M.E. Pharmaceutical applications of cyclodextrins: Effects on drug permeation through biological membranes. J. Pharm. Pharmacol. 2011, 63, 1119-1135. [CrossRef] [PubMed]

23. Loh, G.O.K.; Tan, Y.T.F.; Peh, K.-K. Enhancement of norfloxacin solubility via inclusion complexation with $\beta$-cyclodextrin and its derivative hydroxypropyl- $\beta$-cyclodextrin. Asian J. Pharm. Sci. 2016, 11, 536-546. [CrossRef]

24. Khaoulani, S.; Chaker, H.; Cadet, C.; Bychkov, E.; Cherif, L.; Bengueddach, A.; Fourmentin, S. Wastewater treatment by cyclodextrin polymers and noble metal/mesoporous $\mathrm{TiO}_{2}$ photocatalysts. C. R. Chim. 2015, 18, 23-31. [CrossRef]

25. Moulahcene, L.; Skiba, M.; Senhadji, O.; Milon, N.; Benamor, M.; Lahiani-Skiba, M. Inclusion and removal of pharmaceutical residues from aqueous solution using water-insoluble cyclodextrin polymers. Chem. Eng. Res. Des. 2015, 97, 145-158. [CrossRef]

26. Maragos, C.M.; Appell, M.; Lippolis, V.; Visconti, A.; Catucci, L.; Pascale, M. Use of cyclodextrins as modifiers of fluorescence in the detection of mycotoxins. Food Add. Cont. 2008, 25, 164-171. [CrossRef]

27. Szente, L.; Szemán, J. Cyclodextrins in analytical chemistry: Host-guest type molecular recognition. Anal. Chem. 2013, 85, 8024-8030. [CrossRef]

28. Wu, Q.; Xu, J.; Xu, H. Interactions of aflatoxin B1 and related secondary metabolites with native cyclodextrins and their potential utilization. Food Control 2018, 94, 102-107. [CrossRef]

29. Poór, M.; Matisz, G.; Kunsági-Máté, S.; Derdák, D.; Szente, L.; Lemli, B. Fluorescence spectroscopic investigation of the interaction of citrinin with native and chemically modified cyclodextrins. J. Lumin. 2016, 172, 23-28. [CrossRef]

30. Poór, M.; Kunsági-Máté, S.; Szente, L.; Matisz, G.; Secenji, G.; Czibulya, Z.; Kőszegi, T. Interaction of ochratoxin A with quaternary ammonium beta-cyclodextrin. Food Chem. 2015, 172, 143-149. [CrossRef]

31. Dall'Asta, C.; Faccini, A.; Galaverna, G.; Corradini, R.; Dossena, A.; Marchelli, R. Complexation of the mycotoxin zearalenone with $\beta$-cyclodextrin: Study of the interaction and first promising applications. Mycotoxin Res. 2008, 24, 14-18. [CrossRef] [PubMed]

32. Galaverna, G.; Dall'Asta, C.; Corradini, R.; Dossena, A.; Marchelli, R. Cyclodextrins as selectors for mycotoxin recognition. World Mycotoxin J. 2008, 1, 397-406. [CrossRef]

33. Maragos, C.M. Recent advances in the development of novel materials for mycotoxin analysis. Anal. Bioanal. Chem. 2009, 395, 1205-1213. [CrossRef]

34. Appell, M.; Jackson, M.A. Synthesis and evaluation of cyclodextrin-based polymers for patulin extraction from aqueous solutions. J. Incl. Phenom. Macrocycl. Chem. 2010, 68, 117-122. [CrossRef] 
35. Shirasawa, T.; Ueda, M.; Appell, M.; Goto, T. Use of cyclodextrin-based polymer for patulin analysis in apple juice. Mycotoxins 2013, 63, 1-8. [CrossRef]

36. Appell, M.; Jackson, M.A. Sorption of Ochratoxin A from Aqueous Solutions Using $\beta$-CyclodextrinPolyurethane Polymer. Toxins 2012, 4, 98-109. [CrossRef]

37. Poór, M.; Faisal, Z.; Zand, A.; Bencsik, T.; Lemli, B.; Kunsági-Máté, S.; Szente, L. Removal of Zearalenone and Zearalenols from Aqueous Solutions Using Insoluble Beta-Cyclodextrin Bead Polymer. Toxins 2018, 10, 216. [CrossRef]

38. Loftsson, T.; Brewster, M.E. Pharmaceutical Applications of Cyclodextrins. 1. Drug Solubilization and Stabilization. J. Pharm. Sci. 1996, 85, 1017-1025. [CrossRef]

39. Durán-Merás, I.; Muñoz de la Peña, A.; Salinas, F.; Rodríguez Cáceres, I. Spectrofluorimetric determination of nalidixic acid based on host-guest complexation with $\gamma$-cyclodextrin. Analyst 1994, 119, 1215-1219. [CrossRef]

40. Lucas-Abellán, C.; Fortea, M.I.; Gabaldón, J.A.; Núñez-Delicado, E. Complexation of resveratrol by native and modified cyclodextrins: Determination of complexation constant by enzymatic, solubility and fluorimetric assays. Food Chem. 2008, 111, 262-267. [CrossRef]

41. Csepregi, R.; Lemli, B.; Kunsági-Máté, S.; Szente, L.; Kőszegi, T.; Németi, B.; Poór, M. Complex Formation of Resorufin and Resazurin with B-Cyclodextrins: Can Cyclodextrins Interfere with a Resazurin Cell Viability Assay? Molecules 2018, 23, 382. [CrossRef] [PubMed]

42. Faisal, Z.; Kunsági-Máté, S.; Lemli, B.; Szente, L.; Bergmann, D.; Humpf, H.-U.; Poór, M. Interaction of dihydrocitrinone with native and chemically modified cyclodextrins. Molecules 2019, 24, 1328. [CrossRef] [PubMed]

43. Tu, Y.-S.; Tseng, Y.J.; Appell, M. Quantum chemical investigation of the detection properties of alternariol and alternariol monomethyl ether. Struct. Chem. 2019. Article in Press. [CrossRef]

44. Molina, P.G.; Zón, M.A.; Fernandez, H. Determination of the acid dissociation constants for some mycotoxins of the Alternaria alternata genus. Can. J. Chem. 1998, 76, 576-582.

45. Sali, N.; Csepregi, R.; Kőszegi, T.; Kunsági-Máté, S.; Szente, L.; Poór, M. Complex formation of flavonoids fisetin and geraldol with $\beta$-cyclodextrins. J. Lumin. 2018, 194, 82-90. [CrossRef]

46. Cozzini, P.; Ingletto, G.; Singh, R.; Dall'Asta, C. Mycotoxin Detection Plays "Cops and Robbers": Cyclodextrin Chemosensors as Specialized Police? Int. J. Mol. Sci. 2008, 9, 2474-2494. [CrossRef]

47. Verrone, R.; Catucci, L.; Cosma, P.; Fini, P.; Agostiano, A.; Lippolis, V.; Pascale, M. Effect of $\beta$-cyclodextrin on spectroscopic properties of ochratoxin A in aqueous solution. J. Incl. Phenom. Macrocycl. Chem. 2007, 57, 475-479. [CrossRef]

48. Dobretsov, G.E.; Syrejschikova, T.I.; Smolina, N.V. On mechanisms of fluorescence quenching by water. Biophysics 2014, 59, 183-188. [CrossRef]

49. Sebestyén, Z.; Buvári-Barcza, Á.; Rohonczy, J. pH-dependent complex formation of amino acids with $\beta$-cyclodextrin and quaternary ammonium $\beta$-cyclodextrin. J. Incl. Phenom. Macrocycl. Chem. 2012, 73, 199-210. [CrossRef]

50. Bom, A.; Bradley, M.; Cameron, K.; Clark, J.K.; van Egmond, J.; Feilden, H.; MacLean, E.J.; Muir, A.W.; Palin, R.; Rees, D.C.; et al. A novel concept of reversing neuromuscular block: Chemical encapsulation of rocuronium bromide by a cyclodextrin-based synthetic host. Angew. Chem. Int. Ed. Engl. 2002, 41, 265-270. [CrossRef]

51. Ioi, J.D.; Zhou, T.; Tsao, R.; Marcone, M.F. Mitigation of Patulin in Fresh and Processed Foods and Beverages. Toxins 2017, 9, 157. [CrossRef] [PubMed]

52. Pascari, X.; Ramos, A.J.; Marín, S.; Sanchís, V. Mycotoxins and beer. Impact of beer production process on mycotoxin contamination. A review. Food Res. Int. 2018, 103, 121-129. [CrossRef] [PubMed]

53. Vila-Donat, P.; Marín, S.; Sanchis, V.; Ramos, A.J. A review of the mycotoxin adsorbing agents, with an emphasis on their multi-binding capacity, for animal feed decontamination. Food Chem. Toxicol. 2018, 114, 246-259. [CrossRef] [PubMed]

54. Castellari, M.; Versari, A.; Fabiani, A.; Parpinello, G.P.; Galassi, S. Removal of Ochratoxin A in Red Wines by Means of Adsorption Treatments with Commercial Fining Agents. J. Agric. Food Chem. 2001, 49, 3917-3921. [CrossRef] [PubMed] 
55. Faisal, Z.; Fliszár-Nyúl, E.; Dellafiora, L.; Galaverna, G.; Dall’Asta, C.; Lemli, B.; Kunsági-Máté, S.; Szente, L.; Poór, M. Cyclodextrins Can Entrap Zearalenone-14-Glucoside: Interaction of the Masked Mycotoxin with Cyclodextrins and Cyclodextrin Bead Polymer. Biomolecules 2019, 9, 354. [CrossRef] [PubMed]

56. Waterhouse, A.L. Wine Phenolics. Ann. N. Y. Acad. Sci. 2002, 957, 21-36. [CrossRef] [PubMed]

57. Odlaug, T.E.; Pflug, I.J. Thermal Destruction of Clostridium botulinum Spores Suspended in Tomato Juice in Aluminum Thermal Death Time Tubes. Appl. Environ. Microbiol. 1977, 34, $23-29$.

58. Ayawei, N.; Ebelegi, A.N.; Wankasi, D. Modelling and Interpretation of Adsorption Isotherms. J. Chem. 2017, 2017, 1-11. [CrossRef]

59. Poór, M.; Kunsági-Máté, S.; Sali, N.; Kőszegi, T.; Szente, L.; Peles-Lemli, B. Interactions of zearalenone with native and chemically modified cyclodextrins and their potential utilization. J. Photochem. Photobiol. B 2015, 151, 63-68. [CrossRef]

60. Harada, A.; Furue, M.; Nozakura, S. Cyclodextrin-containing polymers. 2. Cooperative effects in catalysis and binding. Macromolecules 1976, 9, 705-710. [CrossRef]

61. Harada, A.; Furue, M.; Nozakura, S. Inclusion of aromatic compounds by a $\beta$-cyclodextrin-epichlorohydrin polymer. Polym. J. 1981, 13, 777-781. [CrossRef]

62. Szemán, J.; Ueda, H.; Szejtli, J.; Fenyvesi, E.; Machida, Y.; Nagai, T. Complexation of several drugs with water-soluble cyclodextrin polymer. Chem. Pharm. Bull. 1987, 35, 282-288. [CrossRef] [PubMed]

63. Seo, T.; Kajihara, T.; Miwa, K.; Iijima, T. Catalytic hydrolysis of phenyl esters in cyclodextrin/poly(allylamine) systems. Makromol. Chem. 1991, 192, 2357-2369. [CrossRef]

(C) 2019 by the authors. Licensee MDPI, Basel, Switzerland. This article is an open access article distributed under the terms and conditions of the Creative Commons Attribution (CC BY) license (http://creativecommons.org/licenses/by/4.0/). 